\title{
3 Migration
}

In a globalized world, we need to make mutual enrichment possible while countering xenophobic attitudes. Measures for the democratic governance of cultural diversity at the national, regional, and local levels ought to be swiftly adapted: "democratic citizenship and participation should be strengthened, intercultural skills should be taught and learned, spaces for intercultural dialogue should be created" (EAC 2014, 9). History of philosophy ought to become attentive to migration because migration accompanies the whole history of civilizations, involving continuous relations and exchanges among cultures, hence translations through different linguistic, economic, political, and cultural contexts. In recent years, there has been a surge of humanities-led migration studies. Think of attempts at providing an overall philosophy of migration (Di Cesare 2017), of studies on Kant on migration (Reinhardt 2019), and specific contributions on the ethics and politics of migration (Wellman and Cole 2012; Carens 2014; Sager 2016; Mendoza 2017), on space, place, borders, and territory (Appadurai 1996; Low and Lawrence-Zúñiga 2003; Moore 2015; Nail 2016), on displacement and legal constraints (Penz et al. 2011; Pevnik 2011) as well as on narratives of migration (Gomez-Estern 2013; De Fina and Tseng 2017).

I start the chapter by showing that the methodological approach I am looking into is different from the one pursued in the studies quoted above, which are defined by disciplinary methodologies. The method I am considering is cross-disciplinary and has been experimented with during the lifetime of the Migration Project of the National Research Council of Italy, which dates back to 2008 and has been constructed by Maria Eugenia Cadeddu upon an idea proposed by Tullio Gregory (Pozzo 2019). The idea is that research on migration ought not to be reduced to emigration or immigration processes of populations or ethnic groups. It ought to also consider translations (in their broadest sense) of texts and competencies from one to another context, be it linguistic, economic, political, or cultural. I then look into the contiguity of history of philosophy and migration narratives, beginning with Kant and ending in recent experiences of displacement in translocalities, and I conclude with remarks for kick-starting a strategic research and innovation agenda on migration.

\subsection{Holistic Approach}

The phenomenon of migration in the sense of human mobility in its complex and articulated shape embraces a series of socio-economic and cultural aspects

Ә OpenAccess. (c) 2021 Riccardo Pozzo, published by De Gruyter. (cc))BY-NC-ND This work is licensed under the Creative Commons Attribution-NonCommercial-NoDerivatives 4.0 International License.

https://doi.org/10.1515/9783110709292-004 
that have a substantial bearing on security, healthcare, environmental, and nutritional issues. Research on migration finds its place at the frontiers of science insofar as it integrates technological innovation with social innovation and eventually with cultural innovation, thus providing substantial added value to citizens of a global community. Migration is not a stand-alone topic. It connects to broader themes such as climate change, economy, international relations, gender, social policies, and many more. We are looking at a growing community of researchers who work on migration. What used to number around $10-15 \%$ of $\mathrm{SSH}$ researchers is now increasing due to the cross-disciplinary aspects of the thematic area, which require interaction with the whole SSH domain as well as with life sciences and medicine, environmental sciences, logistics, agrofood, and information and communication technology (ICT).

Migration has become a benchmark of political decision-making and a decisive segment of society's economic, environmental, ethical, sanitary, and cultural development. The recurring migrants and refugees crises of the first two decades of the twenty-first century pose a challenge whose dimensions are comparable to those of the ecological crisis of the last quarter of the previous century, whose icons were the acid rains; it was overcome through an epochal effort in research that brought about not only an industrial reconversion but also a change in the mindset of the citizens, namely green thinking. Migration asks for a paradigm shift that involves all disciplines in the direction of a new hybrid consideration. Top-down modeling of phenomena finds a unique synthesis with the discovery of new cognitions bottom-up, which emerge from the immense masses of available data. The main goal is to deal with every aspect of science and technology related to migrants, migration, and integration.

Migration is expected to become a substantial growth factor, starting with the effective management of the reception and integration supply chains. It has been acknowledged that migrants are generators of innovation and networks, as documented in several case studies analyzed in Italy (Chiesi and De Luca 2012). Migrants are less and less contained within the borders of states. They leave and go, keeping in touch with their countries of origin and with resident communities in the countries of destination. Missing integration has high costs due to its physical and economic impact on migrant subjects and the receiving society. Migration has a connection with welfare and its efficient use: in an ever-growing world population, welfare plays a fundamental role because migrants affect its implementation. Migration asks for a societal reflection that is historical, philosophical, legal, and religious and that promotes and revitalizes experiences of co-existence and systems of peacemaking in the relations of cultures. 
The control of migration flows, the protection of migrant lives, and the prevention of terrorism are primary necessities related to security. These requirements entail controlling the borders in their various forms (sea, land, and unconventional routes) by accounting explicitly for the need not to delay first humanitarian aid operations. The predisposition to develop diseases is partly dependent on ethnicity and country of origin. Still, it can be profoundly modified by environmental, cultural, socio-economic, lifestyle changes and the associated stresses occurring in the country of settlement. There is a urgent need to understand these interactions and plan effective screening and integration strategies to preserve incoming and resident people's health and reduce impact on national and regional healthcare systems. It is also essential to face the perception of citizens on the risk of contagious diseases adequately.

Finally, migration is in most cases either due to current changes in the terrestrial ecosystem or caused by political, demographic, and economic conditions, on top of which the environment is an amplifying factor for the deterioration of living conditions. The diverse stress factors on the human being and the environment are connected, although water management remains the primary cause. Biodiversity is to be studied concerning the mobility of migrants, which has an impact on the agro-food system. It is necessary to combine global climate change models with local scenarios of social and economic growth.

\subsection{Kant on Migration}

Migration has become, in recent years, a highly controversial issue in politics, in the media, and with the public. Karoline Reinhardt (2019) has dedicated a welldocumented and well-argued monograph to what we can learn from Kant's stance on migration. Her main argument revolves around the assumption that Kant's views about cosmopolitanism lie in productive disharmony with the philosophical and political camps currently represented in migration debates.

In the first part, "Geschlossene Grenzen-Offene Grenzen,” Reinhardt deals with the debate about closed versus open borders in contemporary political philosophy (Pevnik 2011). She distinguishes three leading positions in the current discussion: communitarianism, egalitarian cosmopolitanism, and liberal nationalism, which she discusses with reference, respectively, to Michael Walzer (1994), Joseph H. Carens (2013), and David Miller (2016).

In the second part, "Kants Weltbürgerrecht," Reinhardt addresses the question of the extent to which Kant provides arguments in his writings that deal with migration issues and are useful for current debates-in particular in Zum ewigen Frieden and the Rechtslehre of the Metaphysik der Sitten. Reinhardt shows that 
Kant's arguments on the right of visit (das Recht eines Fremdlings), on hospitality (hospes) and sovereignty (hostis) can be effectively used as the basis for shaping new forms of philosophy of migration, first and foremost because in the commentary to the third definitive article of Zum ewigen Frieden Kant states that "[o]riginally, no one has more right [Recht] than another to live on a particular place [Ort] on the earth." While looking at late-eighteenth-century colonialism, Kant envisaged a form of ius cosmopoliticum (Weltbürgerrecht), whose consequence is universal hospitality (allgemeine Hospitalität), which is to be acknowledged as the right of the foreigner (das Recht eines Fremdlings) to freedom of movement, although hospitality does not entail the right of the foreigner to rob, exploit, and enslave (Zum ewigen Frieden AA8: 358[1-13] CE [Frieden] 329; Metaphysik der Sitten AA6: 352[6]-355[30]; CE [MdS] 489-492, Rechtslehre $\S$ 62; Di Cesare 2017, 98-101; Reinhardt 2019, 224). ${ }^{29}$ At the center of Reinhardt's consideration is Kant's notion of cosmopolitan right, which she refers to as the systematic basis for justification. Reinhardt provides insightful clarifications of the two terms cosmopolitan and cosmopolitanism and the syntagma cosmopolitan right (Reinhardt 2019, 87-88). Significantly, she reminds that Kant's notion of cosmopolitan right emerges in the context of two central concepts: hospitality and colonialism. Hospitality implies the right of everyone arriving in a state not to be treated with hostility. Concerning colonialism, Reinhardt gives evidence of a shift in Kant's position: while in the early writings he admits colonialism, later he takes up a critical stance against violent European expansionism and the enslavement of overseas people (Reinhardt 2019, 146-154).

Reinhardt argues that Kant can contribute substantially to contemporary debates on migration, provided-she makes it very clear-one does not confine Kant behind the simplistic screen of moral universalism. Kant does not pledge himself to the notion that moral equality of all men and women ought to translate itself into the political equality of migrant men and women. Reinhardt maintains that translating moral equality into political equality implies a misunderstanding of the justification basis of cosmopolitan right, which might be seen instead as an innate right of men and women. Thus, she proposes an alternative strategy of justification that includes the conditions of human existence (Reinhardt 2019, 210). Reinhardt emphasizes Kant's resistance to some of the current demands of moral universalism. She shows that Kant was in no way in favor of open borders and universal freedom of movement (Reinhardt 2019, 66). Generally, Reinhardt provides a survey of many critical objections to Kant's views on migration, hospitality, and colonialism, to which she replies by reconstructing the

29 "ursprünglich aber niemand an einem Orte der Erde zu sein mehr Recht hat als der Andere.” 
reasons based on which Kant might have countered them. It is essential to point out that while doing this, she is neither concerned with any apology or even apotheosis nor with an unconditioned updating of Kant's positions.

In the third part of her book, "Weltbürgerrecht und Migration," Reinhardt examines Kant's cosmopolitanism with respect to issues such as refugee status, legitimate and illegitimate grounds for refusal, statelessness, naturalization, the right to emigrate, individual duties of assistance, and cosmopolitan attitude. Her focus is on three thematic issues. First, does global citizenship meet the moral requirements of refugees for first admission? Second, how can one differentiate legitimate and illegitimate grounds of exclusion for migration movements other than flight? Third, how to handle statelessness and naturalization? (Reinhardt 2019, 210) Referring to Pauline Kleingeld's (2011) interpretation, Reinhardt shows how Kant's cosmopolitanism might be seen as an anticipation of today's non-refoulement rule, which forbids a country receiving asylum seekers from returning them to a country where they are at risk of serious human rights violations and would be in likely danger of persecution based on race, religion, nationality, membership of a particular social group or political opinion (Reinhardt 2019, 212). Reinhardt concludes that one of the great strengths of Kant's notion of cosmopolitanism lies in its negative wording. It does not constitute a total obligation to admit, but it does constitute a complete legal obligation not to refuse (Reinhardt 2019, 224).

On top of legal considerations, Reinhardt also highlights the moral dimension of the duties of aid and philanthropy (Reinhardt 2019, 289-294). For Kant, gratitude, and many other civil attitudes such as sympathy and charity all "lie at the basis of morality, as subjective conditions of receptiveness to the concept of duty" (Metaphysik der Sitten AA6: 399[8-10]; CE [MdS] 528). Reinhardt insists on Kant's describing the obligation to "sympathize" with others, for he claims we have "an indirect duty to cultivate the compassionate natural (aesthetic) feelings in us and to make use of them as so many means to sympathy based on moral principles and the feeling appropriate to them" (Metaphysik der Sitten AA6: 457[26-29]; CE [MdS] 575; Reinhardt 2019, 295). ${ }^{30}$

In this ground-breaking book, Reinhardt does not merely provide an overview of the current debate on cosmopolitan right; she also outlines a Kantian theory of migration, upon which scholars can draw when the time comes to provide visions for the declaration of global mobility that the United Nations is ask-

30 "weil sie als subjective Bedingungen der Empfänglichkeit für den Pflichtbegriff, nicht als objective Bedingungen der Moralität zum Grunde liegen.”-“indirecte Pflicht, die mitleidige natürliche (ästhetische) Gefühle in uns zu cultivieren und sie als so viele Mittel zur Theilnehmung aus moralischen Grundsätzen und dem ihnen gemäßen Gefühl zu benutzen.” 
ing scholars and policymakers to begin working on, likely sooner rather than later. In a nutshell, Reinhardt shows that Kant's philosophy on the right of visit, hospitality, and sovereignty can serve as a basis for shaping new forms of philosophical reflection on migration.

\subsection{History of Philosophy and Migration Narratives}

The history of humanity is a history of mobility. However, political philosophy has often operated under the assumption of a global situation of stasis in which migration is ignored or treated as pathological and exceptional, which is too bad, for migration can indeed serve as a touchstone to prove how philosophy, in its historical dimension, might grant a shared narrative of what has happened, what is happening, and what will happen in our globalized world. In this context, historians of philosophy are to be trusted to achieve what Hannah Arendt (1963) did achieve for the Holocaust in her reporting of the Eichmann trial, Jürgen Habermas $(1991,1994)$ for citizenship in the aftermath of German reunification, and Donatella Di Cesare (2017) for a philosophy of migration after the countless deaths at sea of August 2015.

The first philosophical text that has addressed a twentieth-century personal migration experience is Hannah Arendt's short essay We Refugees (1943). Arendt depicts migration as a global phenomenon and the refugee as an exceptional figure, whose irreducible atopy is bound to create a new world order (Di Cesare 2017, 43). Giorgio Agamben has elaborated on the notion of the "bare life" of the persecuted person (Agamben 1979, 79-83). Managing migration has been a persistent challenge since the 1990s, even if numbers have shifted dramatically. Think of boat migration across Europe's Southern borders and the significant legal, technological, and humanitarian issues it has raised. Hence, the set of "boundary problems" questions the relation of people to the land and calls for deterritorialization as an alternative to identitarian integrity (Di Cesare 2017, 53).

A philosophical consideration of migration presupposes critical analysis of different accounts of what the problem is, what mechanisms are at work, and what the effects of different interventions will be of varying policy narratives on security in receiving countries, protection for migrants, cooperation with countries of origin and transit. The length of time that migrants have resided in a country affects their expectations from society and their own expectations in life. Time is experienced as both linear and rhythmic and involves dimensions such as postponing, waiting and hoping for the future (Erdal and Ezzati 2016). 
In front of the danger that contingent concerns be emphasized at the expense of philosophical rigor, we must acknowledge we have not yet developed a sophisticated understanding of what to say about the rights of would-be immigrants to cross borders and the rights of states to close borders (Sager 2016). Can we talk of a general human right to freedom of interstate migration?

We can think of a worst-case scenario in which unilateralism, economic crisis, and inequality dominate the world in 2030. International cooperation is at its lowest; there is a large financial gap between the European Union and Africa and Asia. Social inequalities (Scanlon 2018) are on the rise, causing social unrest. Under this scenario, the European Union interstate integration project is on the brink of falling apart. Protectionist and isolationist policies are the norm as more countries consider leaving the European Union and abandoning some hard-won global agreements. Very few applicants are granted asylum, and visas are generally difficult to obtain. Since Asia and Africa have not seen relevant economic growth in the past decade, there is a vast economic divide between these sending regions and the European Union (Acostamadiedo et al. 2020).

We can also think, however, of a best-possible scenario in which multilateralism and inclusive economic growth dominate. In 2030, global economic growth and strong international cooperation create more inclusive and diverse societies in the European Union, Africa, and Asia. Governments and civil society rally to implement an ambitious agenda towards multilateralism, openness, and environmental protection. Member states address the needs of migrant populations through a rights-based approach. Sustained economic growth rates in the developed world and high and equitable growth in emerging and developing countries have narrowed development gaps between the European Union and low-income countries of origin. Labor markets in the European Union and developing countries offer young populations attractive job opportunities (Acostamadiedo et al. 2020).

First and foremost, one ought to keep in mind the multidisciplinary character of endeavors on philosophy of migration, which aim to construct a multivoice approach led by the communities of philosophers, historians, geographers, and anthropologists. Each fulfills a specific function while interacting with the others: philosophers are trusted to form focus groups with stakeholders, enterprises, and policymakers; historians point to processes of change; geographers look into spaces and places where migrants move and settle; and anthropologists are in charge of social behaviors. This has led to a broader understanding of the process of knowledge generation.

The continent of all migrants dispersed everywhere globally is enormous and challenges all world-order borders (Massey et al. 1998; Held 1999; Hoerder 
2002; Nail 2015). Against this people arise states, the bulwarks of the old-world order, of the obsolete nómos (vó $\mu$ os) of the Earth. Hence, the sharp conflict between state sovereignty and the right to migrate between restricted citizenship and new deterritorialized citizenship (Di Cesare 2017, 105). We are looking into empowering the disadvantaged, the poor. The dichotomy between "forced" and "voluntary" migration remains dominant in research and policy, apparently resistant to decades of critical analyses. However, the distinction between refugees and migrants has become slippery. On the one hand, it offers a pedagogically convenient way of describing a complex landscape; on the other, its unsettling is politically contentious since it might seem to undermine the individual rights and vulnerabilities of refugees (Di Cesare 2017, 122; see Agier and Madeira 2017; Erdal and Oeppen 2018).

The notion that immigrants impose social costs on the receiving countries reflects the underlying assumption that the imposition of social costs by democratic nation-states on potential migrants is normal, natural, and legitimate (it even becomes questionable whether we can meaningfully talk about social costs in that context). In contrast, the imposition of social costs by migrants on receiving countries is an exceptional event that requires special legitimation (Sager 2017, 66). The conception of immigration policy determines the debate as a field of politics that distributes the good of social membership (as introduced by Michael Walzer [1994]), a good that is "necessarily determined by the members of which these communities are comprised" (Sager 2017, 15).

Today, groups create meaning through multiple memories, whether within the same or across different geographical boundaries. Recent developments are vital in the production of locality, flows, urban and rural landscapes, seascapes, and the migration imaginary, with its repertoire of imagined communities, imagined places, and artworks (Appadurai 1996; Low and Lawrence-Zúñiga 2003; Gupta and Ferguson 2011). Decolonization processes have brought about a shift in the geography of reason:

That knowledge has been colonized raises the question of whether it was ever free. The formulation of knowledge in the singular already situates the question in a framework that is alien to precolonial times. The disparate modes of producing knowledge and notions of knowledge were so many that knowledges would be a more appropriate designation. Unification was a function of various stages of imperial realignment, where local reflections shifted their attention to centers elsewhere to the point of concentric collapse. On their way, those varieties of knowledge coalesced into knowledge of the center, and successive collapses of centers under the weight of other centers led, over time, to the global situation of the center and its concomitant organization of knowledges into knowledge. (Gordon 2011, 95) 
State borders are only one kind of border and a recent kind at that. They crash against pedetic force, kinopolitics, and social kinetics, eventually against critical limology, kinopticism/panopticism, historical limology, surveys, and critiques of the relevant right to control borders (Nail 2016). A comprehensive and systematic account of territory from a philosophical perspective provides insights on issues such as secession, immigration, boundary disputes, resource rights, and historical injustices (Moore 2015; Di Cesare 2017). We need a regime-of-mobility framework that addresses the relationship between mobility and immobility, localization and transnational connection, experiences and imaginaries of migration, rootedness, and cosmopolitan openness (Glick Schiller and Salazar 2013; Kastoriano 2018).

Hannah Arendt (1958) has provided a narrative of the "human condition" by means of a phenomenological characterization of the basic features of the existence of human beings. Arendt's notion of "conscience" can serve as a "subjective but not arbitrary" foundation for a commitment to human rights (Parekh 2008, 153; Birmingham 2008; Guaraldo 2018). Immigration ought to be considered as a right that derives from a people's right to self-determination. Border control cannot obliterate human rights (Parekh 2017; Di Cesare 2017). What about the empowerment of the globally disadvantaged to be normatively central in human rights advocacy? (Meyers 2014) Or should we not rather accept that culture is what we construct whenever we contact other human beings-even though they are from the same environment or not? Can we attach territorial rights to peoples, defined as groups with a distinct political rather than cultural identity? (Salvatori 2010; Moore 2015) Can we talk of the rights of people defined as groups with different cultural identities? (Di Cesare 2017)

Finally, the notion of spiritual citizenship might help to examine how some religiously active migrants appeal to religion to become less deportable. Drawing from ethnographic observations and interviews with Central American and Mexican immigrants in the United States, one sees that undocumented migrants use religion to redefine their sense of self and to position themselves as spiritual citizens of good moral character. Researchers have examined how the priorities of religious organizations operate to and through a neoliberal context. The conclusion is that while religion supports migrants as they endure criminalization, the debate on spiritual citizenship shows how religious participation benefits can also depend on the willingness of migrants to become deserving neoliberal citizens (Guzman Garcia 2016; Ambrosini et al. 2018, 23-24). 


\subsection{Phenomenology of Displacement}

While remaining focused on twenty-first-century dynamics, it is useful to investigate both diachronic and synchronic narratives on encounters of civilizations and consequent challenges. Think of the links connecting early Greek Classical thought with the culture of the ancient Near East (Zuchtriegel 2017; Zonta 2018) and issues related to early-modern geographic discoveries and forced evangelization, e.g., to the emergence of the idea of tolerance in the sixteenth century or to late-eighteenth- and early-nineteenth-century interest for Oriental cultures (Bonacina 2015).

Seventy million people in our world currently live outside the state system, displaced from their countries of origin yet not legally resettled into any country of refuge. Of this group, only one percent will eventually be resettled into a receiving country. The rest will continue to live in a parallel world of temporary solutions. They disappear into large urban centers or are warehoused in refugee camps, while the average duration of stay in these camps is totaling approximately seventeen years (Parekh 2017, 3). Political philosophers have not adequately come to grips with these facts. Doing so requires indeed asking philosophers to develop a new form of ethical analysis focused particularly upon emergency solutions-an "ethics of the temporary," as Serena Parekh terms it (2017, 52).

Migration asks for an innovative narrative of inclusion (Mendoza 2017; Felder 2018). Geography and anthropology are the backbones insofar as they lay out a theory of borders that serves as a premise for a philosophy of territory by looking into the notion of border generally and its economic and sociological aspects. The text of art. 14, comma 1 of the Universal Declaration of Human Rights states: "Everyone has the right to seek and to enjoy in other countries asylum from persecution." 31

Pope Francis himself has pointed to the difference between "immigration" and "invasion." The Holy Father does not think of the development of separate communities in the future. He thinks instead of the fusion of cultures based on the identity of the host country. On 4 October 2020, Pope Francis signed the encyclical letter, Fratelli Tutti, in which he pleaded for citizens worldwide to "welcome, protect, promote and integrate" migrants. The "true worth of the different countries of our world is measured by their ability to think not simply as a country but also as part of the larger human family. This is seen especially in times of

31 https://www.un.org/en/about-us/universal-declaration-of-human-rights, visited on 6 May 2021. 
crisis." Immigrants are not "usurpers," they are first and foremost human beings. Time has come for "envisaging and engendering an open world." 32

\subsection{Diasporas}

Diasporas have transferred and transcribed cultural experiences from one to the other historical and geographic context, following diverse cultural and political supremacies (Sheffer 2013). One promising way to go within the domain of "anthropological studies of multiculturalism and multicultural settings" is backward into history to appreciate better "other kinds of experiences and processes of mobility and admixture within the global ecumene" (Vertovec 2010, 9, 13; see Hannerz 1996; Berque 2000; Ravitch 2008).

Aristotle explains that habits are second nature. The first nature of human beings ensures the continuity of the species or the group, but no progress in the sciences and the arts, which results from habits. One habit is cooking; another is hunting, while eating is no habit: it is a function of our organism. Does language belong to first or second nature? As long as it remains oral, Vico (2003) called the language of the bestioni sufficient suitable to express proximity of prey to catch and predators to flee-eligendo bono et fugiendo malo. Spoken language is natural. It remains first nature. Second nature means acculturation, which is about the changes of social, psychological, legal, and educative habits brought about by migration that require putting into written words diverse cultural experiences, in which the linguistic element (the transfer of texts) is essential (Sgarbi 2012, ix-x).

The Chinese high-school student imagined above in chapter 2 belongs to the Chinese diaspora, which Tu Weiming calls the second symbolic universe of cultural China, namely, "Chinese communities throughout the world ... members of the Chinese 'diaspora', meaning those who have settled in scattered communities of Chinese far from their ancestral homeland" (Tu Weiming 2010, 14). Cultural China (wenhua Zhongguo 文化中国) does not mean tradition against innovation (Tu Weiming 2010, 167). It depicts a dynamic reality instead. The Chinese diaspora (huaqiao 华侨) is “hungry for cultural expression” (Tu Weiming 2010, 21) in spatial and temporal contiguity (Ma Mung 2012, 352). The syntagma people of Chinese origin (huaren 华人) stands for a person that is not geopolitically centered. In contrast, the people of China (zhonghuaren 中华人) necessarily evoke

32 http://www.vatican.va/content/francesco/en/encyclicals/documents/papa-francesco_ 20201003_enciclica-fratelli-tutti.html, visited on 6 May 2021. 
obligations and loyalties of political affiliations and the myth of the Middle Kingdom.

How to open up Chinese philosophy to the world? (Heubel 2021) How to create a translational network to understand the meaning of being Chinese within a global context? (Tu Weiming 2010, 23) Is cosmopolitanism in its Kantian notion (Kleingeld 2011; Benhabib 2011) eurocentric or, in a more specific sense, a form of European particularism? Instead of membership in determinate cultural groups, whose boundaries are clear and whose stability and cohesion are secure, we can talk of "cultural cosmopolitanism," which is the view of mobile cultures that are "subject to constant change, like the people that express them and the individuals of which they are composed" (Taraborrelli 2015, 87). Validation is the result of a process of comparison and exchange. Due to the impact of economic globalization on migration, nation-states ought to consider embracing a multicultural identity centered on loyalty to liberal democratic constitutional principles (Kymlicka 2011; Ley 2011).

In a post-industrial knowledge-intensive economy, globalization is "seen as a process integrating local economies into the world economy" (Tapper 2010, 235). The notion of nation is "so deeply implicated in the texture of everyday life" and so thoroughly presupposed in academic discourses on "culture" and "society" that it "becomes difficult to remember that it is only one, relatively recent, historically continuous form of organizing space in the world. National identity appears to be firmly spatialized and seemingly immutable," as if it were a natural "marker of cultural and social difference." It is interesting to problematize instead nationalism "by juxtaposing it, and other forms of spatial commitment and identity, particularly transnational ones," e.g., the nonaligned movement and the European Union (Gupta 2003, 321, 325). The construction of post-sovereign moral geographies (Appadurai 2003, 337) for the "production of locality, as a dimension of social life, as a structure of feeling, and in its material expression in lived copresence" (Appadurai 2003, 338) must come to terms with the matter of fact that:

the human movement characteristic of the contemporary world is as much a threat to the nation-state as are the attachments of local subjects to local life. The isomorphism of people, territory, and legitimate sovereignty that constitutes the normative charter of the modern nation-state is under threat from the forms of circulation of people characteristic of the contemporary world. (Appadurai 2003, 338)

Translocalities come in many forms as an emergent category of human organization, e.g., due to global economic processes-Hong Kong, Vancouver, and Brussels; e.g., due to civil wars-Sarajevo, Beirut, Belfast, and Mogadishu (Appadurai 2003, 339). There is a cultural form of liberalization alongside economic liberal- 
ization that "invites citizens who have moved abroad to reinvest in their nations of origin, especially if they have not switched passports. India, for example, has the category of Non-Resident Indian” (Appadurai 2003, 340). For many national citizens:

\begin{abstract}
the practicalities of residence and the ideologies of home, soil, and roots are often disjunct. The territorial referents of ... loyalty are increasingly divided for many persons among different spatial horizons ... work loyalties, residential loyalties, and religious loyalties may create disjunctive registers of affiliation.... From the point of view of the nation, there is a rapidly growing distance between the promiscuous spaces of free trade and tourism, where national disciplines are often relaxed, and the spaces of national security, ideological reproduction, which may be increasingly nativized, authenticated, and culturally marked. The Sir Lankan state encourages remarkable cultural promiscuity and "inauthenticity" in its beach resorts (which are now explicitly pushed into a translocal Caribbeanstyle aesthetic) while intensively nationalizing other spaces, which are carefully marked for enacting "Sinhala" national development and "Buddhist" national memory. (Appadurai 2003, 341)
\end{abstract}

Today, there is a consensus that the international migrant ought to be defined as any person who moves to a country other than that of his or her usual residence, any person who crosses at least one national border. Unlike the immigrant, who has come to stay, the migrant is usually thought of as someone in transit who comes to work, travels across our territories and cities, and goes back home or leaves for elsewhere. Geographers consider that the concept of a migrant is based on the physical criterion of movement in space so that the migrant must not be confused with the foreigner, a concept based on a legal criterion. A foreigner is anyone who does not have the nationality of the country in which he or she resides, a quality subject to change following national policies concerning nationality acquisition. Defined with respect and by contrast with the sedentary, the concept of a migrant immediately excludes anything to do with the figure of someone with roots (Diminescu 2008, 566).

The generic divide between migrant, foreigner, immigrant, nomad, and sedentary today tends to blur. Anthropologists have stopped talking of ethnic migration. These concepts do not hold up well in a world given to generalized mobility and unprecedently complicated means of communication. They are talking instead of migrants in multiethnic contexts (Amin 2004). Thus, it is increasingly rare to see migration as a movement between two distinct communities, belonging to widely separated spaces and characterized by independent social relations systems. On the contrary, it is more common for migrants to maintain remote relations based on proximity and activate them daily. The paradigmatic figure of the uprooted migrant is yielding to another model-one that is as yet ill-defined but which corresponds to that of a migrant on the move who relies 
on alliances outside his/her group of belonging without cutting his/her ties with the social networks at home (Diminescu 2008, 566-567).

The anthropology of migration has witnessed the steady growth of transnationalism as perhaps its main topic of interest (Vertovec 2010, 3). Given that "cultural shock derives from the distress of intercultural contact experiences," those abilities that make an individual effective in intercultural communication and adaptation should also "reduce cultural shock, especially those aspects that reduce primary aspects of culture shock: stress reactions, communication problems, and disrupted interpersonal and social relations" (Winkelman 2010, 71).

The apologue of the Chinese student (see chapter 2) sheds light on first-generation migrants, whose "prospect of adaptation cannot be gleaned from the experience of their parents" (Portes 2010, 191). Growing up in an immigrant family has always been difficult, "as individuals are torn by conflicting social and cultural demands while they face the challenge of entry into an unfamiliar and frequently hostile world. Nevertheless, the difficulties are not always the same" (Portes 2010, 192). At times, fortunately more often than not, "the children of contemporary immigrants" become "incorporated into the system of stratification in the host society." In this case, we are talking of "segmented assimilation" (Zhou Min 2010, 74).

\subsection{Strategic Research and Innovation Agenda on Migration}

Throughout history, and certainly over the last hundred years or more, argues Steven Vertovec, immigrants have stayed in contact with families, organizations, and communities in their places of origin and elsewhere in the diaspora. However, in recent years, "the extent and degree of transnational engagement have intensified due largely to changing technologies and reduced telecommunication and travel costs. Enhanced transnationalism substantially transforms several social, political and economic structures and practices among migrant communities worldwide" (Vertovec 2010, 84). Migration and the integration of diverse populations in liberal democratic and pluralist societies call for comparative research and joint programming. Migrants are people (Nail 2015). They are individuals and groups: their rights, their stories, their motivations, expectations, and aspirations, etc. Migration is a process that involves the geopolitics of the countries of origin, the main migration routes, the destination countries and why, the fight against illegal migrations, human rights, and international law, and questions about global inequalities and development, etc. Integration is the response receiving countries can provide: creating bonds between generations and different communities (Pozzo et al. 2022a). 
Let me start with the general definition of a political agenda as the list of subjects or problems to which governmental officials, and people outside the government closely associated with those officials, are paying some serious attention at any given time, after John Kingdon. It is within a political agenda that a research agenda-the exploration, engagement and prioritization, integration, programming, implementation-is laid out to make explicit what are the requirements set out by the nation-state for researchers to relate their studies to real-world issues to validate their research and access research funding allocated by a government. A research agenda is about assessing various research options, which in turn leads to recommendations for a re-orientation of political decisionmaking.

A systematic mapping of studies on migration shows that a vast research effort has been carried out over the last decades. Funding programs and instruments from the past have played a vital role in this. There have been substantial opportunities to further develop knowledge on migration by focusing on understudied topics and promoting systematic knowledge accumulation of existing research..$^{33}$ Migration is an essential factor in increasing cultural, ethnic, and religious diversity within receiving societies. On top of economic issues, migration poses questions of social and cultural integration, raises tensions about dominant values or prevailing traditions, stresses the limits of the institutional makeup of receiving countries with the quest to accommodate new populations with different cultures and needs.

Our understanding of how migratory decisions are made in the real world remains somewhat limited. More specifically, how do macro-level factors (e.g., development, conflict, climate change) shape micro-level aspirations to migrate? Analyzing how structural and individual elements interact is necessary to understand why people move. This area is particularly interesting for development, foreign policy, and humanitarian initiatives, as they try to assess better how their interventions impact migration and forced displacement. Among other disciplines, behavioral economics and social psychology provide insight into how actors decide, migrate, where to go to (or from), how to migrate, when to relocate, etc.

Governments consider influencing the drivers of irregular migration and forced displacement as part of their strategic objectives. Still, key questions remain on how a state can leverage its instruments and whether its goals are realistic and coherent. Besides, this questioning needs to extend to other migration

33 https://migrationresearch.com/, visited on 6 May 2021. 
flows-e.g., how European interventions influence students who wish to come to Europe.

Policies often distinguish between different types of migration flows, and policymakers need data and analyses on newcomers' profiles to design adequate migration, asylum, and integration policies. However, more research is required on how these categories work out in practice, to what extent they reflect the different profiles of migrants, and the effects of policies on these categories or flows. It is crucial to study the impact of migration policies and the general social and economic systems on internal and external migration flows. Analyzing mobility is beneficial for exploring policy implications more comprehensively. More specifically, a research and innovation agenda ought to examine what are the consequences of the recent large-scale refugee intake for the upcoming family mobility; the new geographies of labor migration, what role changes in wage differentials play in both, what are the factors affecting changes in migration temporalities (permanent, temporary, circular, seasonal, short-term, etc.), how these are affected by uncertainties and exclusion.

There is a comparably strong focus on human smugglers and traffickers in migration studies. Compared to this, there is less research on regular agents such as work recruitment agencies, student mobility consultants, or marriage agents, which is surprising when considering how many regular migrants use their services. Also, digital migration studies are an emerging field of interest. Finally, there is little research on the interface of migration and tourism or migration and travel logistics. Notably, transportation means, such as carriers, airports, havens, or bus and train stations, are widely neglected in migration research.

There has been significant research on migration and diversity policymaking at the European, national, regional, and local levels. However, much less is known of how governance actors make decisions in real-world settings. On top of focusing on evaluating policy outcomes, it is interesting to focus on policy decision-making. This can lead to significant contributions to the quality of migration governance. It can cover topics as evidence-based policymaking, how to cope with social complexity, how to cope with contestation and politicization, how to cope with incident-driven politics, etc.

How to focus research funding? The definition of funding programs currently takes a very significant amount of time. This makes it challenging to bring together experts and do research on more immediate topics on the agenda. In recent years, funding schemes have favored either short technical assistance projects conducted by small teams of experts or long large-scale research projects by large consortia of research institutions. This leaves a gap for mediumscale medium-duration projects by medium-size research teams to produce 
more targeted and faster results. This suggests that further diversification of funding schemes would be beneficial. It is expected that funding organizations could become more responsive by providing longer and long-term oriented research projects and shorter and smaller short-term oriented projects. This enables the use of knowledge and research for more immediate issues on the policy agenda, and it could be a stepping stone towards longer-term projects. Funding programs ought to be built on what is already there, which not only prevents overlaps in research; it also promotes systematic knowledge accumulation and enables a focus on areas that need more or new research.

Stakeholders are entities affected by policies that contribute to public understanding of scientific research, improve trust in science, and co-construct research endeavors by providing diverse perspectives. Stakeholders of a strategic research and innovation agenda are ministries, research funding organizations, research performing organizations, universities, companies, small and medium enterprises, unions, non-governmental organizations. Stakeholders are involved, in different capacities, in the definition of sustainable funding programs for the future.

To gain a comprehensive and deep understanding of the multitude of aspects relevant for migration, it is essential to foster collaboration with civil society, policymakers, practitioners, and businesses at local, national, and international levels. These actors rely on knowledge that is internal to their practical involvement with migration issues, which is not immediately accessible to academic researchers. However, given that stakeholders do not always have time to reflect on the use of the knowledge beyond their immediate everyday work aims, it is important to stress that collaboration between academic researchers and practitioners in a broader sense is mutually beneficial in order to gain a more nuanced picture on how migration is played out in broader contexts of social reality.

To grasp the global dimension of migration, cooperation with partners from developing countries is crucial. We can only understand migration better when we know its root causes. Collaborations within the scholarly migration community can be of substantial mutual benefit to enhance the overview of and accessibility to available research, promote knowledge accumulation opportunities, and foster the likelihood of research being used by stakeholders. Philosophers ought to consult migration case studies in legal literature more often, and practitioners of migration governance might welcome impulses from philosophy. Think of the role scholars play for establishing humanitarian corridors as a government practice mixed with private sponsorship, for organizing bottom-up actions to create legal channels, in particular as regards highly vulnerable people, or think of the role they play in fostering interreligious dialogue, globally, as an 
identity element and bridge with the country of origin as well as in receiving societies through dynamics of resilience and possible integration for migrants. ${ }^{34}$

What prospects? Overall, the future agenda on migration is growing through different steps to address research gaps and ensure a longitudinal perspective in high-interest areas for policymakers. Although crisis-oriented, the policy push for coherence produces a shift towards a more systemic approach to migration studies for more organic, wide-ranging, and policy-relevant research results on migration. This effort coincides with research programming strategic trends, such as the increased focus on multidisciplinary research, larger-scale projects with a higher number of partners and countries covered between participants and research areas, and a higher combination of research methods.

From 2014 to 2020, through Horizon 2020, the European Union has funded a wealth of research on migration. More than forty projects on migration received funding, with an average budget of 2 million euros (ranging from 1 to 5 million euros) and an average duration of 3.5 years, mixing SSH and science, technology, engineering, and mathematics (STEM).

One should consider various research initiatives funded under national schemes and other research bodies (public and private) that add to the European Union-funded migration research. While this indeed allows for a sound body of evidence in the different research areas and policy fields, the lack of coordination among multilevel funding also generates incoherence and confusion. Stronger efforts to ensure coordination, at least among European Union financing instruments on migration research and studies, and possibly with national funding schemes, would be of advantage for the research community and policymakers. Most importantly, there is now a need to ensure synergies and coordination among projects exploring the different dimensions of migration. Findings and tools elaborated or developed by the various tasks must be discussed in a coordinated and thorough fashion.

\subsection{Migration Compact}

Out of Egypt, Moses led the Jews (Exodus 13,17-14,29), a collective process, and Joseph the Holy Family (Matthew 2,13-23), an individual process. Many examples of mass and individual migration are found in late antiquity and in the early Middle Ages in Europe. Think of religious refugees such as the Quakers and the Huguenots, the displacement of American native tribes, racism, and

34 https://reires.eu/, visited on 6 May 2021. 
its consequences. Think of displaced persons, the 450,000 Nansen passport bearers after World War I, refugees from Central Africa, etc. It is perhaps time historians of philosophy start reflecting, observing, and interpreting phenomena of exodus as they have been mirrored through visual arts, literature, music, and cinema, creating heroes, ideals, and propaganda. Significantly, Kant states that "a regard to universal communicability is a thing which everyone expects and requires from everyone else, just as if it were part of an original compact dictated by humanity itself" (Kritik der Urteilskraft AA5: 297[15-17]; CE [KU] 177). ${ }^{35}$ A migration compact is needed to ensure that competition for deterrence regarding welfare does not end up in universal impoverishment. If people vote xenophobic, there is a reason for that, and philosophers must take charge of an answer. Today democracy is under attack. Many see democracy as an obstacle on the way to a global economy in which all are producers and consumers. Ought we to give up the truth in democracy for the sake of civil peace? Migration requires careful consideration of its ethical and political effects-personal identity, gender, cultural and religious diversity (Nida-Rümelin 2006; Lau 2016).

European governments do well in elaborating on a migration compact. Furthermore, research has precisely the task and the duty to support political decision-making. On 25 April 2016, commenting on the victory of the extreme right in the first round of the Austrian presidential elections in a "peaceful country where political forces gave all guarantees of peaceful stability," Claudio Magris noted that if the two parties that for decades had assured stability were so blatantly defeated, "this means that the danger of a barbaric Europe is real and that this Austrian warning bell should be heard and not simply and morally deplored."36

In recent years, democracy had to face attacks by fanatics motivated on a religious basis or claiming to be such and had to deal with economic models that consider democracy an alleged obstacle on the road to a world economy dominated by economic giants, where all are producers and consumers of goods and services traded globally. This crucial issue was enucleated by Julian NidaRümelin (2006) into a particular question: In a democracy, ought we not to renounce truth on behalf of guaranteed civil peace? There are, therefore, political reasons to dedicate oneself to the role of truth in democracy. Nevertheless, since

35 "die Rücksicht auf allgemeine Mittheilung von jedermann, gleichsam aus einem ursprünglichen Vertrage, der durch die Menschheit selbst dictirt ist."

36 Magris 2016, 26: "che lo straordinario successo dell'estrema destra abbia avuto luogo in un Paese tranquillo, in cui le forze politiche che lo hanno governato danno tutte le garanzie di pacifica stabilità ... significa che il pericolo di un'Europa barbarica è reale e che questo campanello d'allarme austriaco va ascoltato e non semplicemente e moralisticamente deplorato." 
there is no safe way to separate the true beliefs from the false beliefs, which always remain revisable, what is left for us then? Democracy is not an obstacle towards establishing a global economic order with its supernational structures. We need democracy to achieve in the year 2030 the Sustainable Development Goals laid out by the United Nations in $2015 .{ }^{37}$ Among the challenges to tackle are the rights to asylum, housing, health and social care, employment, education, integration, economic growth, social peace, security.

37 https://sdgs.un.org/goals, visited on 6 May 2021. 
